\section{Os significados de saúde na relação sexual para mulheres assistidas pelo SUS na cidade de Natal, Rio Grande do Norte, Brasil}

\author{
The meaning of health in sexual relations according \\ to women treated under the Unified National \\ Health System in Natal, Rio Grande do \\ Norte State, Brazil
}

\author{
1 Universidade Federal do \\ Rio Grande do Norte, Natal, \\ Brasil. \\ 2 Universidade do Estado do \\ Rio Grande do Norte, Natal, \\ Brasil. \\ Correspondência \\ M. K. M. Cunha \\ Universidade Federal do Rio \\ Grande do Norte. \\ Rua Pedra Branca 35B, Natal, \\ RN 59108-330, Brasil. \\ mkmc06@hotmail.com
}

\section{Abstract}

The aim of this article is to discuss the social representations of "health in sexual relations" as reported by women treated under the Unified $\mathrm{Na}$ tional Health System (SUS) in Natal, Rio Grande do Norte, Brazil. A total of 150 women were tested using the free word recall test, with "health in sexual relations" as the stimulus. Women were also asked about their sources of information on the subject. The results were obtained with content analysis and the EVOC software. We identified three representational dimensions: prevention, relationship with the partner, and quality of life. The central nucleus of social representation consisted of the elements "prevention" and "condoms". Likely sources for representation were television, health services, and dialogue with family members and partners. Representations were composed of concepts related to prevention, a good partner relationship, and overall wellbeing. The results illustrate the need to expand women's sexual health aspects that are considered relevant by the health system.

Sexual and Reproductive Health; Women's Health; Coitus; Perception
Magnus Kelly Moura da Cunha 1,2 Maria Helena Constantino Spyrides 1 Maria Bernardete Cordeiro de Sousa 1

\section{Introdução}

A saúde sexual humana é uma dimensão da saúde que envolve múltiplos fatores biológicos, psicossociais e culturais. Diversos estudiosos em saúde pública têm sugerido que a promoção da saúde sexual e a adoção de políticas de prevenção a doenças sexualmente transmissíveis (DST) eficientes não prescindem da compreensão dos significados, valores e atitudes, ou do conhecimento da normatividade e moralidade presentes em cada população no que se refere a este tema. Para Leal 1, as relações afetivas e sexuais de grupos de pessoas são estruturadas por um conjunto de significados oferecidos pela cultura, sendo tecidas com base em questões de gênero, posições socioeconômicas e especificidades regionais. Além disso, a própria sexualidade é baseada em relações sociais nas quais são importantes a hierarquia, as expectativas do indivíduo e os significados sociais compartilhados pelo seu grupo de pertença.

Desde que os movimentos feministas e de reforma sanitária conduziram o país à criação do Programa de Assistência Integral à Saúde da Mulher (PAISM) em 1983, e do Sistema Único de Saúde (SUS) em 1988, tem-se procurado romper com abordagens reducionistas e fragmentárias à saúde sexual feminina, a exemplo do que ocorre nas demais áreas da saúde. Até então, a atenção à mulher era pautada apenas na aptidão desta para gerar e cuidar dos filhos. Diante dessa nova 
realidade, ainda em construção, outros enfoques têm sido propostos para as pesquisas realizadas nessa área. Trata-se de abarcar outras dimensões da saúde sexual, indo além de seus aspectos biológicos e reprodutivos ou de alguma patologia específica.

Tem sido crescente o número de pesquisas que utilizam a teoria das representações sociais na área da saúde enquanto referencial teórico metodológico, pois esta se constitui em uma ferramenta capaz de abordar de forma muito satisfatória a dimensão subjetiva dos processos saúde/doença. As representações sociais, segundo Moscovici 2, são conceitos, proposições e explicações que indivíduos de um grupo detêm sobre os diversos objetos sociais, expressos durante as comunicações interpessoais e em suas atitudes.

No campo da saúde sexual, os trabalhos com representações sociais foram geralmente circunscritos a AIDS e às atitudes perante a doença. Jodelet 3 , em 1998, publicou estudo com a análise dos processos de elaboração das representações sociais da AIDS e também discutiu as concepções sobre a transmissão da doença. Em pesquisa publicada por Silva 4 em 2002, a autora chamou a atenção para a relevância dos significados de fidelidade e para a pouca percepção de vulnerabilidade a AIDS em um grupo de homens casados. Semelhantemente, um estudo realizado por Tura 5 evidenciou representações sociais que vinculam as atitudes de prevenção à mulher e a permissividade ao homem, enquanto o uso de preservativos aparece relacionado às DST e à desconfiança entre parceiros. Em trabalho realizado por Camargo 6 junto a universitários, o autor encontrou que a AIDS é atrelada à promiscuidade, à desinformação e ao descuido. Mais recentemente, em 2010, Oltramari \& Camargo 7 publicaram um trabalho em que discutem as representações sociais e as atitudes de homens e mulheres que vinculam o contágio com o HIV a pessoas de comportamentos considerados arriscados, e a prevenção ao matrimônio.

Depreende-se com base nos estudos mencionados que a aplicação desse referencial teórico na abordagem à saúde sexual é extremamente útil, o que fica ainda mais claro ao se considerar as funções desempenhadas pelas representações sociais 2: (1) viabilizar a compreensão da realidade: as representações permitem a aquisição de conhecimentos, definindo um quadro de referência assimilável - de códigos, de nomes - e passível de compartilhamento por diferentes indivíduos de um grupo, possibilitando a comunicação e a interação social; (2) orientar os comportamentos e práticas das pessoas: as representações determinam as estratégias cognitivas envolvidas nas ações conforme cada situação enfrentada; (3) justificar, a posteriori, tomadas de posição: enquanto ferramenta de estudo, o reconhecimento das representações sociais permite compreender os motivos da ação expressa no passado diante de contextos específicos; (4) definir e proteger a identidade de grupos: as representações situam os indivíduos em grupos que se diferenciam pelas suas práticas, valores e normas historicamente construídos. Assim, optou-se pela teoria das representações sociais enquanto referencial teórico-metodológico, tendo em vista sua adequação conceitual ao tema saúde sexual, e considerando sua utilidade quando se pretende colocar em evidência aspectos psicossociais relevantes da sexualidade que possam contribuir para adoção de políticas públicas eficazes.

Neste artigo, são apresentados resultados de uma pesquisa que buscou identificar as representações sociais de "saúde nas relações sexuais" para mulheres assistidas por uma unidade de saúde pública especializada em saúde reprodutiva, localizada em Natal, Rio Grande do Norte, Brasil.

\section{Método}

Os resultados aqui apresentados foram obtidos com base em estratégias de coleta de informações e de procedimentos de análise de dados predominantemente qualitativos. A opção por essa perspectiva metodológica se deu pela natureza do objeto de estudo e do referencial teórico utilizado.

\section{Sujeitos}

Participaram deste estudo 150 mulheres recrutadas durante o atendimento no Centro de Saúde Reprodutiva Leide Morais, na cidade de Natal. Considerando-se a natureza da pesquisa, optouse por uma amostragem do tipo não probabilística e de conveniência.

Os critérios de inclusão na amostra foram possuir idades entre 19 e 60 anos e se voluntariar para o estudo. As participantes foram devidamente esclarecidas conforme as normas estabelecidas para pesquisa com seres humanos na Resolução $n^{\circ}$. 196/96, do Conselho Nacional de Saúde, e solicitadas a assinar um termo de consentimento livre e esclarecido. O estudo foi aprovado pelo Comitê de Ética em Pesquisa do Hospital Universitário Onofre Lopes, da Universidade Federal do Rio Grande do Norte (UFRN).

\section{Coleta de dados}

Após rápida ambientação para garantir a espontaneidade necessária das entrevistadas durante 
a coleta de dados, procedeu-se o levantamento das informações sociodemográficas, tais como idade, sexo, estado civil e escolaridade. Em seguida, foram realizados dois exercícios simples, com vistas a prepará-las para o Teste de Evocação Livre de Palauras (TELP) 8 e, logo após, o teste propriamente dito. As participantes foram abordadas individualmente e reservadamente durante a espera por consulta médica, tendo as entrevistas durado de 10 a 20 minutos.

O TELP tem como objetivo fazer emergir as concepções das pessoas acerca de um determinado objeto social, fazendo com que o entrevistado expresse verbalmente estes significados diante de uma expressão estímulo, de forma rápida e tentando evitar censuras ${ }^{8}$. Para isso, utilizou-se como estímulo a expressão "Saúde nas Relações Sexuais”. Recomendou-se às entrevistadas a citação de cinco palavras após sua apresentação. Posteriormente, pedimos a elas para indicar quais das palavras mencionadas eram a primeira e a segunda mais importantes, tendo de apontar uma justificativa para as escolhas. Essa etapa da entrevista foi registrada em gravador digital e os dados convertidos em formato de texto.

Com o intuito de conhecer as possíveis origens dos elementos da representação a ser identificada, foi solicitado que as participantes citassem, em ordem de importância, as principais fontes de informação sobre assuntos relativos à vida sexual e, ainda, com quem costumavam conversar sobre o tema. Também foi perguntado se as mulheres já tinham participado de aula ou palestra sobre assuntos relativos à saúde sexual e em que local isto acontecera.

\section{Análise dos dados}

Realizou-se inicialmente uma leitura flutuante das evocações, no intuito de ter um panorama geral, atentando para os significados presentes e a frequência dos termos. No total, foram evocadas 723 palavras no TELP, somando 162 termos diferentes. Após essa pré-análise, procedeu-se a substituição de palavras lexicalmente diferentes e de significados iguais, ou muito próximos, por um termo comum representativo e fidedigno de seu conteúdo semântico, o que resultou em um banco de 693 caselas preenchidas para análise, contendo agora 109 termos diferentes.

Para fazer emergir os significados da representação em estudo foi realizada uma análise de conteúdo com as 109 evocações, utilizando-se o procedimento de categorização e procurando atender aos critérios prescritos por Bardin ${ }^{9}$ para este tipo de abordagem de dados qualitativos. A categorização realizada baseando-se em critérios semânticos consistiu em agrupar elementos que se identificavam semanticamente sob o título de uma possível categoria, a ser confirmada a partir da consistência de seu próprio conteúdo ao final do procedimento. Com as sucessivas e exaustivas classificações buscou-se a superação da incerteza sobre as categorias, de forma que o máximo de ambiguidades fossem superadas, produzindo uma interpretação generalizável ao conjunto das evocações e assegurando menor dúvida sobre a pertinência dos elementos representacionais nas respectivas categorias. As justificativas das entrevistadas em relação às palavras apontadas como mais importantes foram também utilizadas para esclarecer os significados de parte considerável dos termos evocados.

Para descrever a estrutura da representação identificou-se a composição de seus núcleos central e periféricos, o que serviu também como forma de validação quantitativa do conteúdo da representação. A teoria do núcleo central propõe que uma representação social está hierarquizada em torno de um núcleo central 10, sendo este constituído por elementos representacionais que dão significado à representação. Em torno desse núcleo, organizam-se os seus núcleos periféricos. Esse tem uma função geradora e organizadora e é considerado a matriz a partir da qual se cria ou se transforma a composição da representação, sendo também aquele que mais resiste à mudança. Para a obtenção dos núcleos da representação utilizou-se o programa EVOC-2003 (Ensemble de Programmes Permettant l'Analyse des Evocations), de Verges 11, que os identifica a partir do número de ocorrência das palavras e da ordem em que estas são evocadas durante a aplicação do TELP.

Concomitantemente, foram construídos os perfis sociodemográficos do conjunto das entrevistadas e realizada uma análise descritiva das demais variáveis levantadas.

\section{Resultados}

Do total de mulheres entrevistadas, mais da metade eram casadas $(53,3 \%), 23,3 \%$ disseram ter relação estável com um parceiro, 15,3\% eram solteiras, $6 \%$ divorciadas e apenas $0,7 \%$ viúvas. Quanto ao nível de escolaridade, 49,3\% cursaram o Ensino Médio, 44,7\% o Ensino Fundamental, $0,7 \%$ não era alfabetizada e apenas $5,3 \%$ disseram possuir diploma de nível superior. As idades variaram de 19 a 59 anos, sendo que $40,7 \%$ das idades estavam entre 19 e 30, 42,7\% entre 31 e 46 , $10,7 \%$ entre 47 e 52 , e 5,3\% com idades iguais ou superiores aos 53 anos.

Com base na análise de conteúdo foram identificadas três categorias semânticas, que 
foram consideradas como sendo correspondentes às dimensões constituintes das representações sociais em estudo. Essas dimensões, apresentadas na Figura 1 com seus respectivos elementos representacionais, foram assim denominadas: "prevenção", "relação com o parceiro" e "qualidade de vida".

A dimensão "prevenção" evidencia elementos da representação cujos sentidos principais são a ausência de DST e o conjunto de estratégias e recursos para evitá-las. Essa dimensão é fortemente expressa em palavras que se referem: às próprias doenças, como a "DST"; a recursos que podem ser adotados para evitá-las ou para impedir sua progressão, como a "camisinha" e os "remédios"; e às atitudes, como "cuidado", "prevenção", "higiene” e "responsabilidade”. Já os elementos "unidade de saúde" e "exames", que se referem ao serviço de saúde e aos profissionais e procedimentos médicos adotados, sugerem que ter saúde nas relações sexuais para as mulheres entrevistadas é obedecer àquilo que é proposto pelos profissionais de saúde quanto às medidas de prevenção. Além disso, saúde nas relações sexuais também significa ter "conhecimento" a respeito dos riscos associados à prática sexual desprotegida, daquilo que representa ter uma DST, e quanto às atitudes necessárias à prevenção.

A análise de conteúdo também apontou como relevante a dimensão representacional "relação com o parceiro". Dessa perspectiva, saúde nas relações sexuais também significa obter níveis satisfatórios de qualidade em diversos aspectos da relação sexual-afetiva, seja no que se refere ao ato sexual em si - sentido revelado pelo elemento representacional "sexo" -, seja quanto a ter um parceiro fixo, com quem possa contar e também compartilhar afetos positivos - "companheirismo”, "amor", "carinho", "confiança” -, de quem possa ter "respeito" e esperar "fidelidade" e com quem mantenha um bom nível de "diálogo".

Por último, na dimensão "qualidade de vida" estão presentes elementos como "saúde", cujo sentido é a saúde geral; o "bem-estar", que significa sentir-se bem e satisfeita em diversas áreas da vida; “concepção”, que traduz a necessidade de planejamento familiar e do uso de métodos anticoncepcionais; "família", no sentido de harmonia entre a mulher, esposo e filhos; e a "segurança", que se refere a um sentimento de estabilidade.

Para identificar quais são os elementos mais importantes da representação, ou seja, aqueles que estão mais consolidados e em torno do qual os demais elementos representacionais se organizam, e, ainda, por meio dos quais esses operam e se manifestam, verificou-se quais elementos constituem os seus núcleos central e periféricos. Conforme apresentado na Figura 2, o núcleo central contém os elementos representacionais "prevenção" e "camisinha”, as duas evocações a partir das quais se chegou à dimensão "prevenção”. Já os núcleos periféricos são compostos por elementos de cada uma das três dimensões representacionais. É interessante perceber que nenhum dos elementos das dimensões identificadas usando-se a análise de conteúdo ficou de fora quando os dados foram abordados com a ferramenta (EVOC) da teoria do núcleo central. Nota-se também que a dimensão "relação com o parceiro" teve três de seus elementos com

\begin{tabular}{|c|}
\hline Prevenção \\
Prevenção \\
Camisinha \\
Cuidado \\
Conhecimento \\
DST \\
Higiene \\
Unidade de saúde \\
Exames \\
Remédios \\
Responsabilidade
\end{tabular}

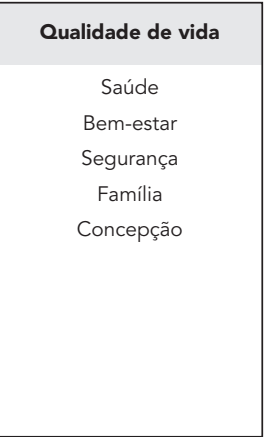


Núcleos central e periféricos da representação social de "saúde nas relações sexuais" de um grupo de mulheres entrevistadas no Centro de Saúde Reprodutiva Leide Morais, Natal, Rio Grande do Norte, Brasil, 2010.
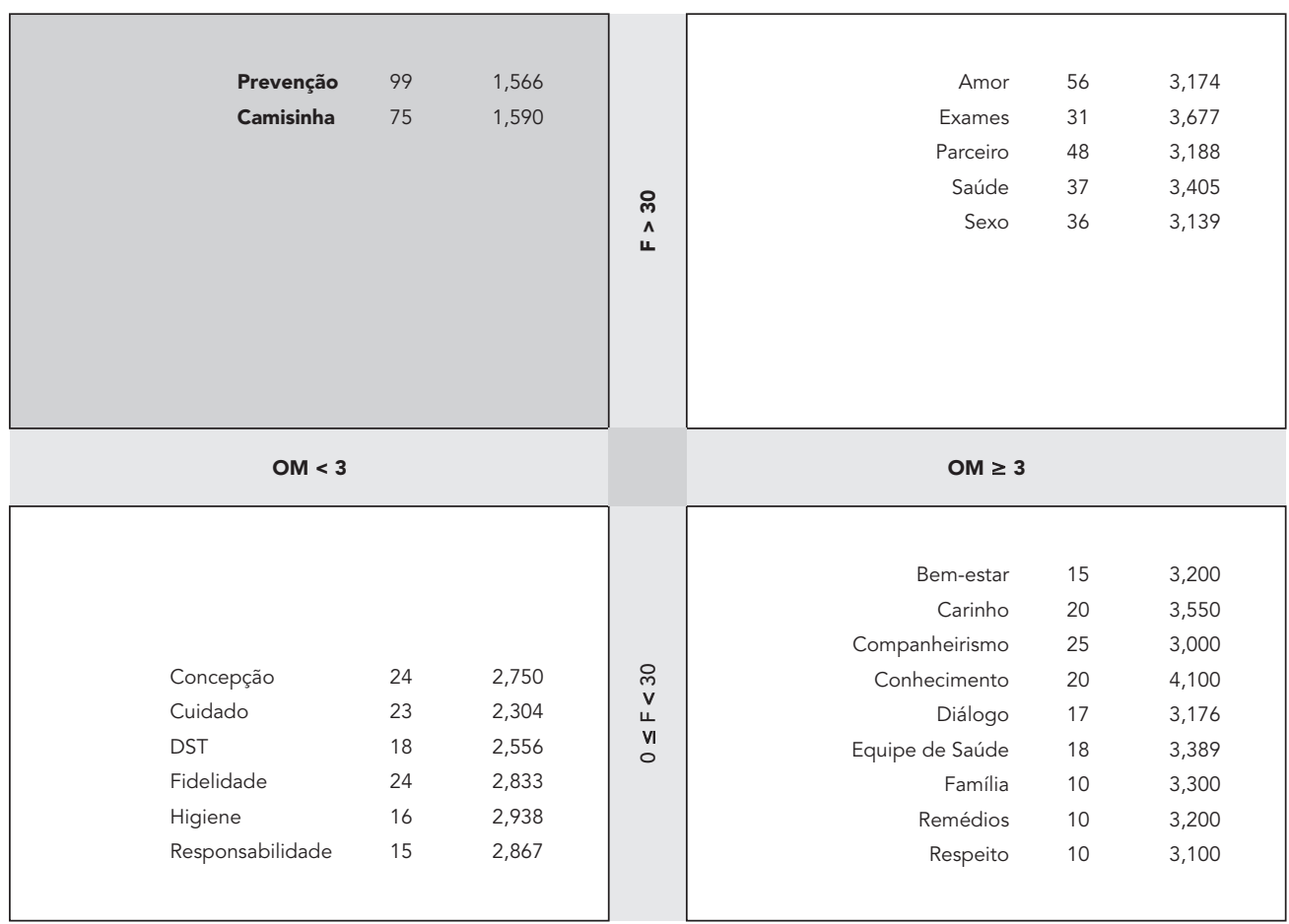

F: frequência; OM: ordem média.

frequência e ordem média praticamente suficientes para também serem considerados constituintes do núcleo central: "amor" ( $\mathrm{F}=56 ; \mathrm{OM}=3,17)$, "parceiro" ( $\mathrm{F}=48 ; \mathrm{OM}=3,18)$ e "sexo" $(\mathrm{F}=36 ; \mathrm{OM}=$ $3,13)$, em que "F" é a frequência das evocações e "OM" corresponde à média da ordem na qual a palavra foi evocada no conjunto dos dados.

As principais fontes de informação apontadas pelas mulheres foram a TV $(43,3 \%)$ e a unidade de saúde (24\%). Elas conversam sobre questões relativas à vida sexual principalmente com familiares $(40 \%)$ e com os parceiros $(28,6 \%)$. A unidade de saúde $(47,8 \%)$ e a escola $(32,7 \%)$ são onde mais as mulheres participaram de palestras sobre o tema. Todos os possíveis doadores de elementos representacionais da representação em estudo estão apresentados na Figura 3.

\section{Discussão}

A presença da dimensão representacional "prevenção" guarda coerência com os resultados de pesquisa de abrangência nacional realizada pelo Ministério da Saúde 12 em 2007, na qual 91\% da população brasileira entre 15 e 54 anos referiram como principal meio de transmissão do HIV o ato sexual, enquanto que o uso da camisinha foi apontado como forma de prevenção da AIDS por 94\% dos entrevistados. A sigla "DST" foi geralmente citada pelas entrevistadas referindo-se a AIDS, o que vincula os sentidos de prevenção aos cuidados em relação ao contágio com o HIV.

Sendo a maioria das mulheres participantes deste estudo $(76,6 \%)$ casada ou com relacionamento estável, essa vinculação de prevenção a AIDS pode significar que, para elas, existe risco de contágio com o HIV mesmo no relacionamento estável. Esses achados são coerentes com o fato de as representações sociais da AIDS, já no início da década de 90, incluírem homens e 
Figura 3

Possíveis origens dos elementos da representação social de "saúde nas relações sexuais" de um grupo de mulheres entrevistadas no Centro de Saúde Reprodutiva Leide Morais, Natal, Rio Grande do Norte, Brasil, 2010.

3a) Fontes de informação

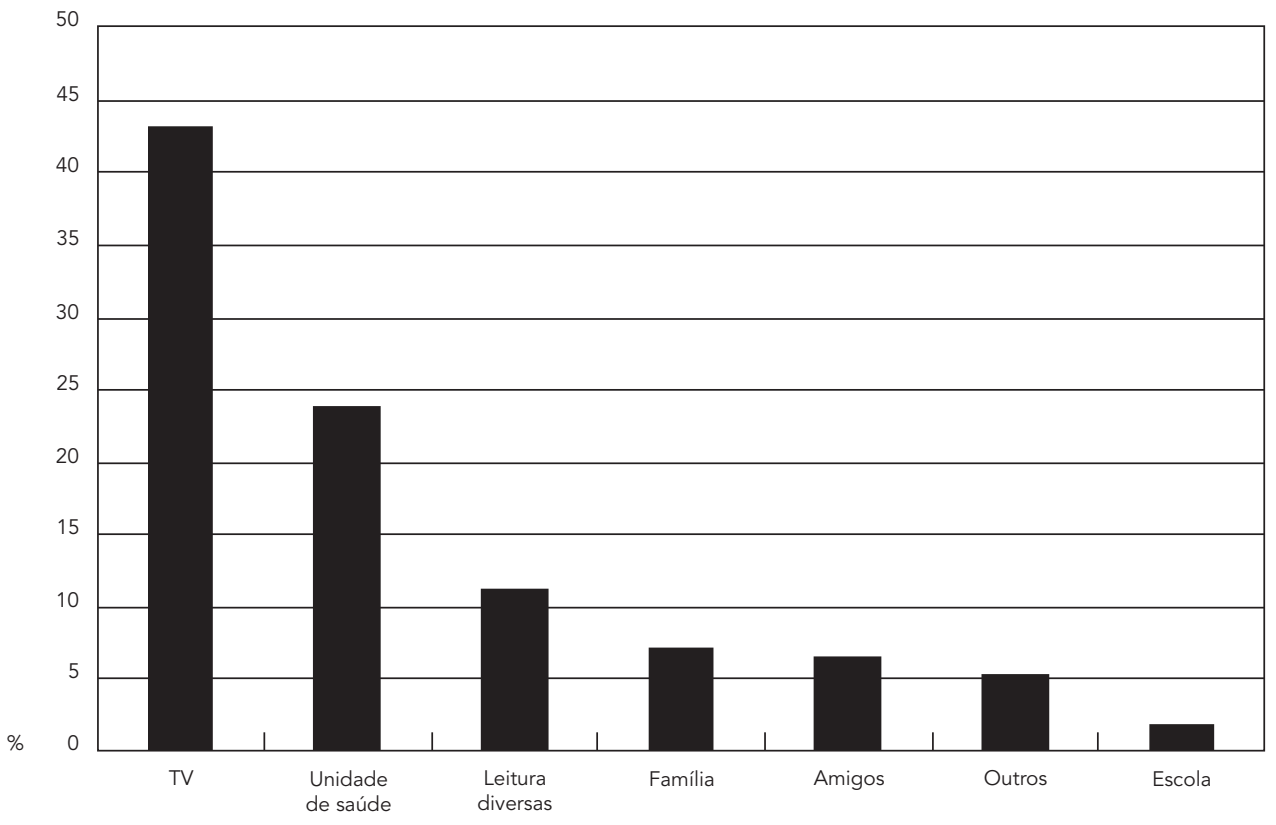

3b) Interlocutores das entrevistadas

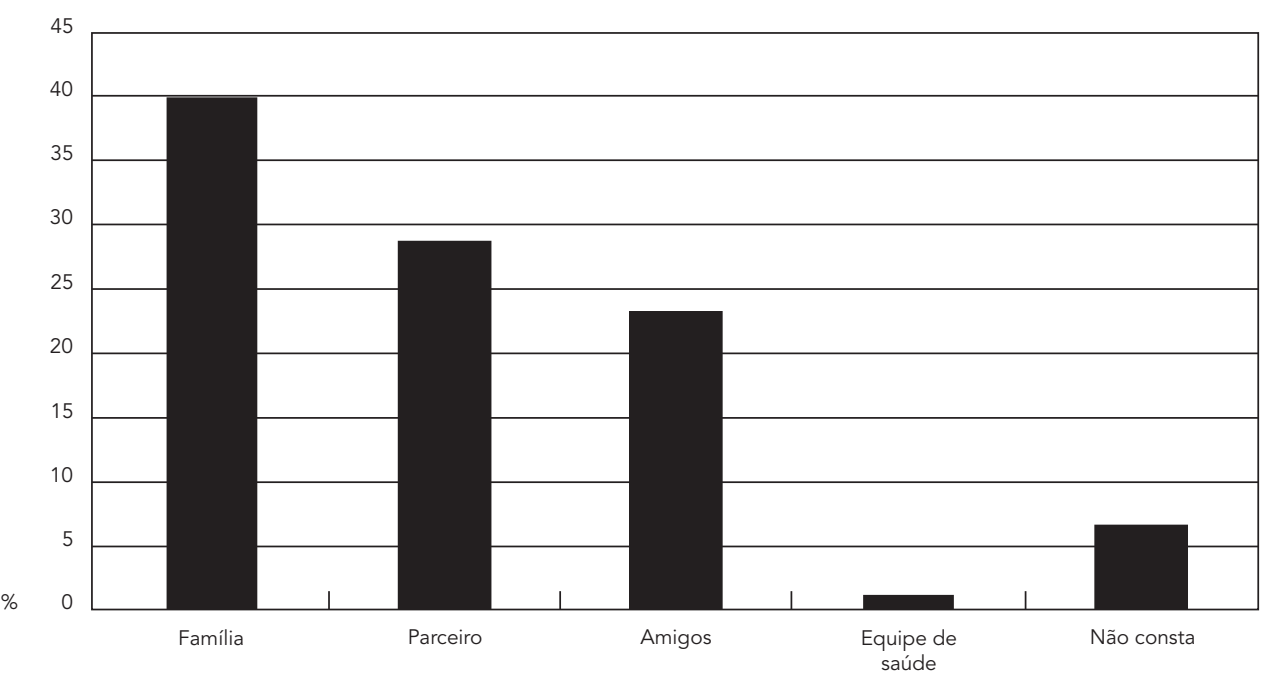




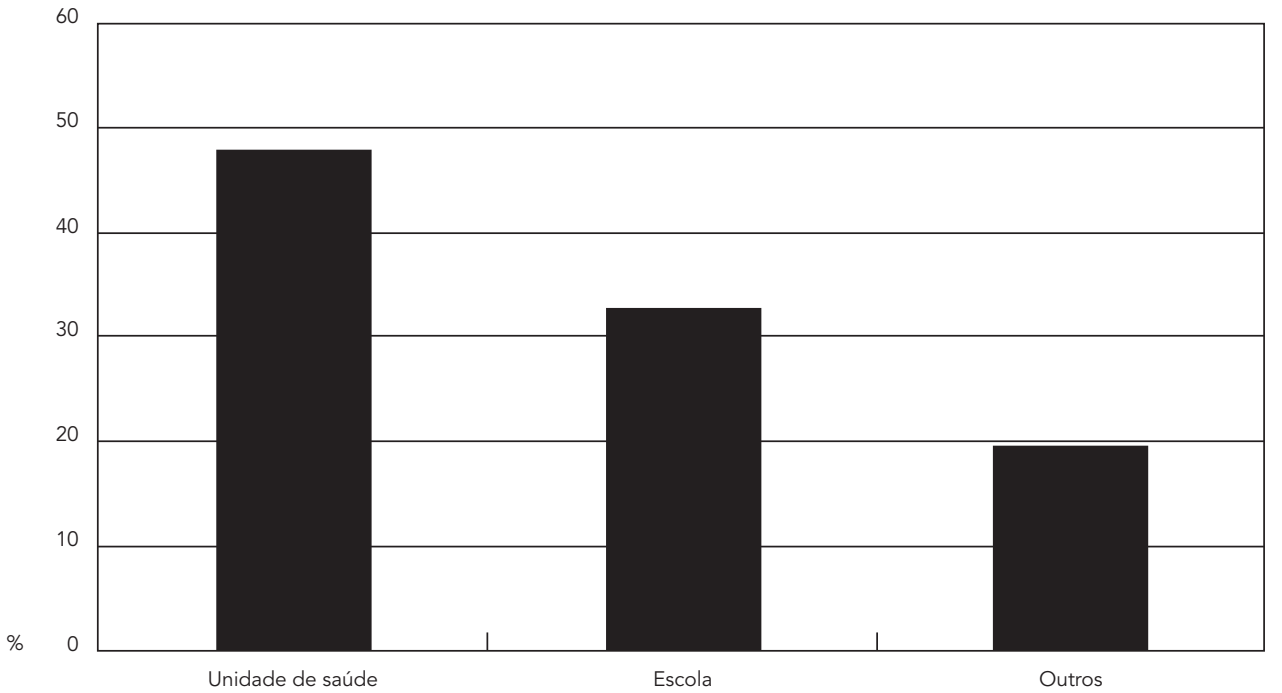

mulheres heterossexuais como não isentos de contágio 13 .

A vinculação do sexo saudável à ausência de DST pode ser atribuída, dentre outras possibilidades, ao fato de algumas destas enfermidades terem deixado marcas profundas na sociedade, devido a muitas vezes terem sido vistas como praticamente incuráveis e mortais durante longo período de tempo, sendo associadas também a comportamentos sexuais moralmente desviantes, como ocorreu com a sífilis e a AIDS e, às vezes, por serem comparadas à peste negra ou ao câncer 14 .

A evocação do conjunto de elementos representacionais da dimensão "relação com o parceiro" pelas mulheres quando inquiridas acerca de saúde nas relações sexuais, não só reafirma que estas são românticas e idealizadoras em relação à vida conjugal, mas também sugere que esta dimensão subjetiva da vida é de extrema relevância à sua saúde sexual. Alguns estudos sistematizados apontam que as mulheres estão mais próximas do prazer no ato sexual quando se sentem com garantia de envolvimento amoroso recíproco e da fidelidade por parte do parceiro. Segundo Basson 15, a intimidade é fator de grande importância, sendo condição fundamental para que as mulheres se sintam motivadas para o sexo. Estudo publicado por Gonzales et al. 16 mostrou que a presença de desejo e orgasmo fe- minino estão diretamente relacionados ao nível de envolvimento emocional entre os parceiros. Para os autores, se há sentimentos positivos recíprocos, isto abre espaço para o diálogo entre os casais e as decisões são tomadas com firmeza, tornando-se mais fácil falar em projeto de vida e tomar decisões importantes, o que concorre para uma vida saudável, com cumplicidade e entrega. Pode ser que esses sejam ingredientes fundamentais ao bom relacionamento, uma vez que representam a compatibilização entre os valores e as motivações com o desejo sexual do casal. É importante ressaltar que em nossa cultura as relações conjugais são balizadas pelos princípios da fidelidade e da lealdade.

Outro fator que também explica a composição representacional da dimensão "relação com o parceiro" é a conquista de autonomia pela mulher nos dias atuais, seja em relação à escolha do cônjuge, seja por sua inserção no mercado de trabalho. Torna-se esperado que ela passe a ter maiores expectativas em relação a um homem que seja companheiro, que divida com ela as responsabilidades domésticas e que seja capaz de viver um relacionamento no qual as relações de poder propiciem maior igualdade entre ambos.

Já os elementos presentes na dimensão "qualidade de vida” sugerem uma vinculação importante entre a satisfação sexual e o bem-estar geral, estando de acordo com um estudo realizado 
por Avis et al. 17, no qual os autores observaram uma associação significativa entre estes dois fatores. Outro estudo realizado na Itália com 355 mulheres entre 46-60 anos, mostrou que o bemestar físico e a saúde mental, mais do que o estado menopausal por si, foram os fatores que mais influenciaram a saúde sexual em geral nesta faixa etária 18.

Os resultados apontam a existência de núcleos central e periféricos na representação social em estudo. Coerentemente com a proposta de classificação dos elementos do núcleo central por Abric 8 , pode-se sugerir que o elemento "prevenção" possui caráter normativo, contendo um significado de saúde nas relações sexuais que concorre para a adoção de posturas e atitudes de prevenção frente à possibilidade de contrair doenças no ato sexual, enquanto que o elemento "camisinha" é de natureza funcional e representa um objeto da prática social operacional, uma forma de proteção durante o coito. No que se refere aos três elementos representacionais da dimensão "relação com o parceiro" - "amor", "parceiro" e "sexo" - caso fossem pertencentes ao núcleo central, se poderia atribuir-lhes um caráter funcional, sendo que a outros elementos desta mesma dimensão, como "fidelidade" e "diálogo", uma natureza normativa.

Segundo a teoria de Moscovici 2, as representações são produtos de processos coletivos de elaboração, difusão e mudança dos conhecimentos compartilhados no cotidiano das pessoas. Assim, elas surgem e são modificadas no contexto das interlocuções, e sua consolidação envolve o discurso circulante nas comunidades. Considerando o número de mulheres que apontaram a TV como fonte de informação sobre assuntos relacionados à vida sexual (Figura 3a), a contribuição deste veículo de comunicação enquanto doador de elementos representacionais para a consolidação da representação aqui descrita parece ter sido bastante relevante. Para entender como pode ter ocorrido essa contribuição, basta lembrar que entre os anos 1990 e 2000 o Ministério da Saúde intensificou as campanhas televisivas de prevenção para o combate à epidemia de AIDS. Considerando-se a idade das participantes deste estudo, constata-se que a maioria delas pertence a uma geração fortemente influenciada por essas campanhas. As principais matérias institucionais veiculadas pela TV nesse período foram: "Você Usa Camisinha" (1996); "Canções Carnaval" (1999); e "Рapo" (2000). Segundo Santos 19, todos esses anúncios tinham como sugestão mostrar a mulher como mediadora na negociação para o uso da camisinha. Paralelamente a isso, também foi instituída a distribuição gratuita de preservativos em unidades de saúde e durante eventos de grande concentração popular como o Carnaval, o que ainda é usual nos dias atuais. Isso justifica em parte o fato de as palavras "prevenção" e "camisinha" terem sido citadas, respectivamente, com frequência 75 e 99 pelas mulheres entrevistadas, o que as situou no núcleo central da representação em estudo. É válido salientar que desde a sua popularização e massificação entre os anos 70 e 80, a TV tem milhões de expectadores que a assistem por várias horas diárias, o que a coloca em situação de grande relevância quando se considera a gênese de representações sociais. Para França et al. 20, a TV instaura saberes, ecoa normatizações, estabelece verdades, ratifica interdições, disciplina o pensamento, constrói desejos, adestra as condutas e hierarquiza as atitudes.

Não é difícil entender as razões porque, para as mulheres pesquisadas, saúde nas relações sexuais tem a ver com "prevenção", "camisinha” e "DST". A ideia de prevenção veiculada pela mídia esteve sempre atrelada ao conceito de risco e, no caso da mulher, esteve constantemente baseada na noção de vulnerabilidade do sexo feminino. Além disso, pode-se admitir que as desigualdades entre os gêneros sempre foram pressupostos que orientaram as campanhas de prevenção em relação a AIDS. Muitas das campanhas também se pautaram na ideia de AIDS como consequência de comportamentos desviantes, da infidelidade e de descuidos individuais no uso da camisinha. Esses fatos explicam em grande parte a presença de elementos representacionais que vão desde as "DST", passando pela "camisinha” e pelo "sexo", até a "fidelidade" e a "saúde”. Para Oliveira et al. 21, as campanhas de prevenção foram importantes para os sentidos que se desenvolveram sobre a AIDS e os fatores nela implicados.

Os resultados aqui apresentados também guardam coerência com as representações da AIDS para estudantes, descritas em anos anteriores. Em 1998, Tura 5 encontrou como núcleo central dessas representações a morte, o sexo, a camisinha e a doença. Já em 2000, Camargo 6 identificou, no núcleo central, os elementos sexo e prevenção, e atribui esta mudança na representação social à participação da mídia nas campanhas de prevenção à doença, o que resultou na adição de novos elementos à representação, uma vez que, no início dos anos 90, a própria mídia ressaltava o aspecto mortal da doença.

A segunda fonte de informação mais citada foi a unidade de saúde, sendo que $47,8 \%$ das entrevistadas disseram ter assistido, pelo menos uma vez, a palestras ou cursos neste serviço (Figuras 3a e 3c). Esse resultado é coerente com o fato de as entrevistadas serem usuárias do Centro de Saúde Reprodutiva Leide Morais, uma unidade de referência do SUS especializada em saúde 
da mulher. Com a criação do SUS, o princípio da integralidade veio no sentido de se contrapor a concepções reducionistas nas ações e políticas públicas voltadas à clientela feminina, que reduzia a saúde sexual da mulher a objetos isolados e descontextualizados. Procurando seguir os preceitos do SUS, essa unidade de saúde tem atuado em diversas frentes e abordado diferentes aspectos da saúde da mulher.

Embora não se tenha neste artigo avaliado objetivamente as possíveis influências das ações do centro de saúde reprodutiva na representação aqui descrita, pode-se sugerir que este, considerando os serviços que oferece e a natureza dos elementos representacionais encontrados nesta pesquisa, tem contribuído, ao lado das campanhas televisivas, para uma concepção de saúde nas relações sexuais fortemente vinculada à prevenção. Essa contribuição é percebida, por exemplo, quando a unidade de saúde é apontada como o local onde mais as entrevistadas participaram de aulas ou palestras sobre o tema (47,8\% das mulheres) e pela presença do elemento representacional "unidade de saúde" na dimensão "prevenção", sendo a unidade de saúde vinculada à "prevenção" e à "camisinha". No entanto, na contramão desse resultado positivo, pode-se sugerir ainda que há dificuldades dos profissionais de saúde na abordagem do tema, pois apenas $1,3 \%$ das mulheres referiu conversar com alguém das equipes de saúde sobre aspectos da vida sexual. Essas dificuldades, possivelmente devidas à existência de tabus e preconceitos que ainda permeiam as questões relacionadas à vida sexual, persistem como entraves à implementação de políticas de saúde mais eficazes no campo da saúde sexual feminina.

As demais fontes de informação citadas pelas entrevistadas se apresentaram com menor frequência que a TV e a unidade de saúde, entre elas a escola. Essa poderia se constituir numa das principais fontes de informação científica para as classes menos favorecidas, o que é a realidade das participantes desta pesquisa. No entanto, ainda há pouca discussão nesse espaço de educação acerca da vida sexual. Para França et al. 20 , a escola e os meios de comunicação buscam apenas garantir normatizações sociais que atendam aos apelos dos discursos hegemônicos sobre sexualidade e as práticas sexuais. Camargo \& Botelho 22 apontam que as campanhas de prevenção contra a AIDS e os conhecimentos adquiridos na escola são, geralmente, apenas prescritivos de normas e condutas consideradas adequadas, Isso implica uma contribuição restrita às representações de saúde nas relações sexuais, uma vez que esse espaço não dá conta de tratar da maioria dos aspectos da vida sexual. É possível que sua maior participação na consolidação da representação aqui identificada tenha ocorrido em relação ao uso de métodos anticoncepcionais e à prevenção contra as DST, que são os temas mais abordados nas escolas. É válido salientar que o nível de escolaridade também pode influenciar na saúde sexual. Abdo et al. 23 sugerem que quanto mais baixa a escolaridade, mais a saúde sexual pode apresentar-se comprometida. Neste estudo, cerca da metade das entrevistadas cursou apenas o ensino fundamental $(44,7 \%)$ e a outra metade $(49,3 \%)$ apenas o ensino médio. No entanto, a representação identificada tem elementos de significados coerentes com aqueles que as abordagens em saúde empregadas nas unidades do SUS pretendem fomentar.

De acordo com a Figura 3b, a maioria das participantes deste estudo conversa sobre sua vida sexual com a família (40\%) e com o parceiro $(28,7 \%)$. É surpreendente o fato de tantas mulheres referirem manter diálogo com o parceiro sobre esse assunto. Porém, isso é coerente com elementos da dimensão "relação com o parceiro”, tais como: “diálogo" e "companheirismo”. É importante destacar que as mulheres sempre foram estimuladas a investir no diálogo com o parceiro, seja porque se tornam mais afetivas que os homens, seja porque são frequentemente encarregadas pelas campanhas de prevenção a mediar o processo de uso de camisinha e a adoção de diversos cuidados 19 . Considerando que a maioria das mulheres tinha relação estável, essa referência ao diálogo com o parceiro está em sintonia com a necessidade de comunicação diante de uma realidade que é o aumento do número de casos de AIDS em heterossexuais, principalmente entre as mulheres, apontado pelo Ministério da Saúde 12 em 2008. É importante ressaltar que o número de mulheres infectadas com o HIV também tem aumentado no último decênio. Em Natal, entre os anos de 1997 e 2003, a razão homem/mulher de contaminados caiu de 4,7/1 para 1,6/124.

Pode-se sugerir que as mulheres aqui pesquisadas apresentam conceitos bastante atualizados, pois sua representação sobre saúde nas relações sexuais favorece a vinculação do ato sexual à prevenção mesmo nas relações estáveis, uma vez que a maioria das pesquisadas tem relação estável. Esses resultados estão em conformidade com as sugestões de Silva 4 em artigo publicado sobre uma pesquisa realizada junto a homens casados em relação à fidelidade e a AIDS, em que a autora defende a ideia de ter havido uma reelaboração das representações sociais acerca dos chamados "grupos de risco", tendo este deixado de existir ou se estendido a qualquer pessoa. Souza Filho 25 também encontrou que para as mulheres a 
prevenção da AIDS pode estar associada à opção por um parceiro único e ao uso de preservativos.

Não se pode negar que o uso de preservativo ou de qualquer outro meio de proteção é sempre uma negociação entre os parceiros, e envolve preconceitos sobre as práticas sexuais e crenças no que deve e como deve ser um relacionamento. Um estudo realizado por Tura 5 evidenciou representações sociais que vinculam as atitudes de prevenção à mulher e a permissividade ao homem, enquanto o uso de preservativos aparece relacionado às DST e à desconfiança entre parceiros. Resultado semelhante foi publicado por Oltramari \& Camargo 26: as representações sociais de mulheres profissionais do sexo vinculam o preservativo a uma vida de risco, que as faz utilizá-lo quando fazem sexo com clientes e a dispensá-lo quando estão com seus parceiros fixos afetivos. Camargo ${ }^{6}$, em pesquisa junto a universitários, encontrou que a AIDS é atrelada à promiscuidade, podendo ser contraída por desinformação ou por descuido. Giacomozzi \& Camargo 27 sugerem que ao se abordar a prevenção, dado o caráter relacional das práticas sexuais, o parceiro também deve ser envolvido, evitando-se deixar a responsabilidade apenas sobre as mulheres. Vale a pena lembrar que o uso do mais importante recurso de prevenção contra as DST, a camisinha, é de total controle dos homens.

A atribuição da função de negociação às mulheres talvez se deva à percepção de que estas, desde a adolescência, são mais controladas pela família, mais vigilantes em relação à gravidez ${ }^{28}$, preocupam-se e cuidam-se mais que os meninos em relação à virgindade e em relação ao contágio com doenças advindas dos homens que, ao contrário delas, levam uma vida sexual mais livre. É válido salientar que os indicadores de saúde sexual-reprodutiva da própria Organização Mundial da Saúde se assentam principalmente sobre o corpo feminino, excluindo o homem do processo, adotando como indicadores de saúde, principalmente, taxas relacionadas diretamente à saúde orgânica da mulher.

Com base nos resultados, pode-se sugerir que as prováveis fontes doadoras de elementos representacionais para a representação social de saúde nas relações sexuais são bastante diversificadas para o grupo estudado, indo desde as interações interpessoais, conversas com parceiros ou família, até as unidades de saúde e a TV. Dessa forma, a representação aqui descrita não é apenas fruto de conhecimentos científicos repassados às mulheres, mas consequência também do contato destas com outros discursos circulantes. É importante lembrar que as representações sociais cumprem a função de tornar o não-familiar - aqui o repertório científico de informações concernentes à saúde nas relações sexuais advindo da unidade de saúde, por exemplo - familiar, possibilitando aos indivíduos se apropriarem de conceitos e definições estranhas à primeira vista 2 .

Faz-se necessário chamar a atenção para a possibilidade de não explicitação de alguma outra dimensão da representação, uma vez que as entrevistadas podem ter ocultado parte dos elementos representacionais 29 , expressando apenas o que julgava adequado ou permitido por seu senso de moralidade, de forma a não se exporem a constrangimentos.

\section{Considerações finais}

Os significados de saúde nas relações sexuais para as mulheres entrevistadas consistem num conjunto de diferentes imagens imbricadas que podem ser sintetizadas como: o cuidado com a própria saúde, expresso por meio dos elementos representacionais prevenção e camisinha, pertencentes ao núcleo central da representação; a satisfação com o parceiro, sentido revelado, por exemplo, pelos elementos amor, parceiro e sexo; e a qualidade de vida, conteúdo representacional manifestado por elementos como bem-estar, saúde, segurança e família. Assim, a identificação das representações aqui descritas reafirma a natureza multifatorial da saúde sexual.

O núcleo central da representação contém os elementos prevenção e camisinha, o que significa dizer que os conteúdos referentes à relação com o parceiro e à qualidade de vida podem ter sido a partir deles estruturados e que, coerentemente, convergem para a garantia da saúde nas relações sexuais. Essa composição do núcleo central pode ser atribuída ao fato de a pesquisa ter sido realizada junto a mulheres assistidas em uma unidade de saúde do SUS especializada em saúde sexual-reprodutiva, na qual são enfatizados os programas de prevenção de DST.

Ficou demonstrado que entre as prováveis fontes doadoras de elementos para a representação destacam-se a TV, a unidade de saúde e as interlocuções com familiares e com o parceiro. Embora não seja possível avaliar a contribuição individual de cada uma delas à representação segundo Moscovici 2, vários fatores psicossociais individuais e coletivos interferem na gênese e na consolidação das representações sociais para tornar as informações passíveis de incorporação à representação -, colocá-las em evidência representa um avanço na compreensão das representações estudadas.

A representação aqui descrita transcende o ato sexual em si e a própria saúde orgânica. Isso 
deve ser entendido como indicador da necessidade de ampliação dos aspectos abordados pelo SUS quanto à saúde sexual para além da questão do uso da camisinha e dos aspectos orgânicos. Sugere-se também o envolvimento do parceiro nas políticas e nos programas de promoção à saúde sexual-reprodutiva e prevenção de DST, uma vez que, como evidenciado neste estudo, a saúde sexual figura como algo de natureza relacional.

\section{Resumo}

O objetivo deste artigo é discutir as representações sociais acerca de "saúde nas relações sexuais" de mulheres atendidas pelo SUS. Cento e cinquenta pesquisadas foram submetidas ao Teste de Evocação Livre de Palavras (TELP), adotando-se como estímulo "saúde nas relações sexuais". As mulheres foram questionadas também a respeito da origem das informações acessíveis sobre o tema. Os resultados foram obtidos utilizando-se a análise de conteúdo e o programa EVOC. Foram identificadas três dimensões representacionais: prevenção, relação com o parceiro e qualidade de vida. O núcleo central da representação social mostrou-se constituído pelos elementos prevenção e camisinha. As prováveis fontes doadoras de elementos para a representação foram a TV, a unidade de saúde e as interlocuções com a família e o parceiro. As representações são compostas por conceitos relativos à prevenção, à boa relação com o parceiro e ao bem-estar geral. Esses resultados são indicadores da necessidade de ampliação dos aspectos abordados pelo SUS em relação à saúde sexual feminina.

Saúde Sexual e Reprodutiva; Saúde da Mulher; Coito; Percepção

\section{Colaboradores}

M. K. M. Cunha participou da concepção, planejamento e desenvolvimento da pesquisa, análise e discussão de resultados e redação do artigo. M. H. C. Spyrides participou do planejamento da pesquisa e da análise dos dados, tendo contribuído também na sistematização dos resultados. M. B. C. Sousa orientou o planejamento e desenvolvimento da pesquisa, e contribuiu com a discussão dos resultados e revisão crítica e final do artigo.

\section{Agradecimentos}

Agradecemos à direção do Centro de Saúde Reprodutiva de Natal, pelo espaço concedido à realização da pesquisa. Às mulheres entrevistadas, pela disponibilidade. A Carol Benigno, pelo auxílio na tabulação das informações. A Karine Symonir, pela contribuição na análise dos dados. À professora Técia Maria de Oliveira Maranhão, pela contribuição na revisão deste artigo. 


\section{Referências}

1. Leal AF. Uma antropologia da experiência amorosa: estudo de representações sociais sobre sexualidade [Dissertação de Mestrado]. Porto Alegre: Universidade Federal do Rio Grande do Sul; 2003.

2. Moscovici S. Representações sociais: investigações em psicologia social. Petrópolis: Editora Vozes; 2005.

3. Jodelet D. Representação do contágio a AIDS. In: Jodelet D, Madeira M, organizadoras. AIDS e representações sociais: à busca de sentidos. Natal: EDUFRN; 1998. p. 17-45.

4. Silva CGM. O significado de fidelidade e as estratégias para prevenção da AIDS entre homens casados. Rev Saúde Pública 2002; 36:40-9.

5. Tura LFR. AIDS e estudantes: a estrutura das representações sociais. In: Jodelet D, Madeira M, organizadoras. AIDS e representações sociais: à busca de sentidos. Natal: EDUFRN; 1998. p. 121-54.

6. Camargo BV. Sexualidade e representações sociais da AIDS. Revista de Ciências Humanas 2000; 3:97110 .

7. Oltramari LC, Camargo BV. AIDS, relações conjugais e confiança: um estudo sobre representações sociais. Psicol Estud 2010; 15:275-83.

8. Abric JC. Méthodologie de recueil des représentations sociales. In: Abric JC, editor. Pratiques sociales et representations sociales. Paris: PUF; 1994. p. 59-82.

9. Bardin L. Análise de conteúdo. Lisboa: Edições 70; 1988.

10. Sá CP. Núcleo central das representações sociais. Petrópolis: Editora Vozes; 1996.

11. Verges L. Ensemble de programmes permettant l'analyse des evocations. Manuel version 2. Aixen-Provence: Lames; 1999.

12. Ministério da Saúde. Boletim Epidemiológico AIDS e DST 2008; ano V(1).

13. Souza Filho EA, Henning MG. Representações sociais da AIDS, práticas sexuais e vida social entre heterossexuais, bissexuais e homossexuais em Brasília, Brasil. Cad Saúde Pública 1992; 8:428-41.

14. Sontag S. Doença como metáfora: AIDS e suas metáforas. São Paulo: Companhia das Letras; 2007.

15. Basson R. The female sexual response: a different model. J Sex Marital Ther 2000; 26:51-65.

16. Gonzales M, Viafara G, Caba F, Molina T, Ortiz C. Libido and orgasm in middle-aged woman. Maturitas 2006; 53:1-10.

17. Avis NE, Zhao X, Johannes CB, Ory M, Brockwell S, Greendale GA. Correlates of sexual function among multiethnic middle aged women: results from Study of Women's Health Across the Nation (SWAN). Menopause 2005; 12:385-98.
18. Nappi RE, Verde JB, Polatti F, Genazzani AR, Zara C. Self-reported sexual symptoms in women attending menopause clinics. Gynecol Obstet Invest 2002; 53:181-7.

19. Santos LHS. Biopolíticas de HIV/AIDS no Brasil: uma análise dos anúncios televisivos das campanhas oficiais de prevenção (1986-2000) [Tese de Doutorado]. Porto Alegre: Faculdade de Educação, Universidade Federal do Rio Grande do Sul; 2002.

20. França FF, Felipe DA, Calsa GC. Gênero, sexualidade e meios de comunicação: uma abordagem crítica desses conceitos na educação. Revista Cesumar 2008; 13:37-53.

21. Oliveira DLLC, Meyer DE, Santos LHS, Wilhelms DM. A negociação do sexo na TV: discursos de gênero nas falas de agentes comunitários de saúde do Programa Saúde da Família de Porto Alegre, Rio Grande do Sul, Brasil. Cad Saúde Pública 2004; 20:1309-18.

22. Camargo BV, Botelho LJ. AIDS, sexualidade e atitudes sobre a proteção contra o HIV. Rev Saúde Pública 2007; 41:61-8.

23. Abdo CH, Oliveira Jr. WN, Moreira Jr. ED, Fittipaldi JA. Prevalence of sexual dysfunctions and correlated conditions in a sample of Brazilian women: results of the Brazilian study on sexual behavior. Int J Impot Res 2004; 16:160-6.

24. Secretaria Municipal de Saúde, Prefeitura Municipal de Natal. Plano municipal de saúde: 20062009. Natal: Secretaria Municipal de Saúde, Prefeitura Municipal de Natal; 2006.

25. Souza Filho EA. Dois estudos sobre representações de práticas sexuais/afetivas no contexto da AIDS no Rio de Janeiro. In: Moreira ASP, Oliveira DC, organizadores. Estudos interdisciplinares de representação social. Goiânia: AB; 1998. p. 215-34.

26. Oltramari LC, Camargo BV. Representações sociais de profissionais do sexo sobre prevenção de doenças sexualmente transmissíveis e contracepção. Psicol Teor Prát 2004; 6:75-87.

27. Giacomozzi AI, Camargo BV. Eu confio no meu marido: estudo da representação social de mulheres com parceiro fixo sobre prevenção da AIDS. Psicol Teor Prát 2004; 6:31-44.

28. Martins DA. A sexualidade sob o ponto de vista de adolescente do sexo feminino [Dissertação de Mestrado]. Ribeirão Preto: Universidade de São Paulo; 2002.

29. Abric JC. A zona muda das representações sociais. In: Oliveira, DC, Campos PHF, organizadores. Representações sociais: uma teoria sem fronteiras. Rio de Janeiro: Museu da República; 2005. p. 23-4.

Recebido em 27/Mai/2010

Versão final reapresentada em 25/Fev/2011

Aprovado em 07/Abr/2011 